\title{
TOTAL SUSTAINABILITY MANAGEMENT. DESCRIBING THE CONDITIONS, REQUIREMENTS AND APPLICATION OF SUSTAINABILITY MANAGEMENT
}

\author{
Stefan BORON \\ Heriot-Watt University \\ Tomasz KOSIEK \\ Silesian University of Technology
}

\begin{abstract}
:
Countless people and organisations have been wrestling with the practical application of sustainability and sustainable development. Yet there is no rigorous and unequivocal template that can be followed for management because the meaning of the key concepts of sustainability and development in particular haven't been properly identified. Although the fundamental meaning of the word sustainability is continuance, the concept has its controversies especially when it drifts into the 'abstract' and even becomes confused with sustainable development. For our purposes it is the ability of development and of its associated processing activities to continue that is being managed. For management effectiveness, a system framework is necessary but more importantly what goes into that system has to be rigorously and unambiguously defined. In our case, the mechanisms describing the practicalities that govern the sustainability of development have been clearly identified in this paper and called by name. The concept of development needs clarification, while the accepted popular 'three pillar' depiction of sustainable development is also fundamentally flawed when compared with the form of words of the 'Brundtland' definition. This well-known 'Venn representation' implies a type of 'balance' or 'synergy' at the heart of sustainability management. In fact, because of the fundamentally unsustainable nature of current development processes, the 'balance' turns into a trade-off amongst the three sustainability players. For real sustainable development there can be no such trade-off. Once the misunderstandings are clarified the true basics of sustainability and sustainable development are fed into a standard ISO14001 iteration loop for management to commence.
\end{abstract}

Key words: sustainability management; 'Brundtland'; real sustainable development; ISO14001

\section{INTRODUCTION}

There are so many perceptions of sustainability that it may be unclear which 'flavour' of sustainability is actually being managed. The idea of development too is not unambiguous. On the one hand, development is associated with wealth creation while according to the thinking of the commission on environment and development (WCED) report Our Common Future (OCF), it is made up of all the activities and processes that contribute to 'the satisfaction of human needs and aspirations' [1].

Sustainability has only one fundamental meaning that of continuance [2] and sustainable development (SD) is therefore a development path that can continue indefinitely. In this paper it is the sustainability of development and of its constituent processes that is being managed. The present lack of transparency regarding the meaning of the key concepts of sustainability, sustainable development, development itself and even the 'environment' serve as a barrier to effective management.
This paper introduces the necessary conditions required for the effective management of sustainability and sustainable development by clarifying exactly what is being managed through the identification, in the first part of the paper, of unambiguous defining criteria for the terms used. In the second part, the identified criteria are introduced into a standard environmental management system framework, making it suitable for sustainability management.

\section{SUSTAINABILITY AND SUSTAINABLE DEVELOPMENT 'REDISCOVERED'}

\section{A dichotomy encountered}

Environmental Management is the 'control' of the interaction with the 'surroundings' of what we do and of the way we do it. [3] It requires (1) a full understanding of the mechanisms and criteria for that interaction, and (2) A vehicle, an organised procedure, like a management system to act as a guide. What goes into a management system is 
all-important. Perception precedes and inspires action and how you see things will determine how they are managed. It is vital to examine your assumptions because the old adage of rubbish in = rubbish out still holds true.

With so many different opinions about sustainability and sustainable development, (SD) doing the rounds, the 'real' ones to be managed must be identified [4].

In the work of training Chemical Engineers for their role in the management of processes, and in particular the management of sustainable development, a dichotomy quickly became apparent. To put SD into practice a robust unambiguous mechanism is indispensable, yet two different representations of SD are ever present (1). The popular triple bottom line (TBL) three pillar 'model' of SD and also (2), the SD definition from the OCF report [1:43]. Although both are used extensively and often together, at first glance there is no apparent or logical connection between them. In calling the TBL model an "intuition" [5] or a "recalibration" of the original OCF definition [6:5], a vain attempt is made at bridging the gap. This kind of argument is hardly scientific and a rigorous resolution of the dichotomy long overdue. How two so different representations can yield an unambiguous practical mechanism required for engineering implementation is the question to be answered.

\section{The dichotomy deciphered}

Sustainability refocused

For a closer scrutiny of what SD actually means, these two "popular" representations were examined in the light of what it says in OCF. The report has long been overlooked as the in depth study of SD that it actually is. The approach is thorough and the results incisive, something that should be obvious to anyone who takes the time to read and fathom what it actually says.

Sustainability - the thing we want to manage - in contemporary usage is far from unequivocal. It's original objective meaning of continence [2] has acquired various subjective shades implying health, integrity and the like [4]. This in effect is an abstract prone to various interpretations and distortions [7] where everyone is free to choose their own brand [5].

In the wake of increasing environmental problems, (Smog, Acid, Climate Change) the WCED was given the remit in 1983 to identify the main features of the interaction between environment and human development and to come up by the year 2000 and beyond with a strategy to achieve a sustainable development, one that did not cause environmental damage. Although sustainability does not figure explicitly in $\mathrm{OCF}^{1}$, its meaning there is unmistakable. From the context of its usage it is unlikely that sustainability in the report means anything other than the ability to continue.

\section{Development from first principles}

Development too has more than one interpretation, and this has a direct bearing on the efficacy of management, affecting the perception of what exactly is being managed.

To carry out its remit, OCF first sets the context for their investigation through an explicit choice of meaning for the key concepts of environment and development.

In the chairman's foreword we read [1:xi], "But the 'environment' is where we all live; and 'development' is what we all do in attempting to improve our lot within that abode" (our emphasis).

Later in chapter 2, development is explicitly cast in the role of need satisfaction rather than the traditional accumulation of wealth. "The word development has been narrowed down by some into a very limited focus along the lines of "what poorer nations should do to become richer" [1:xi] ..."The satisfaction of human needs and aspirations is the major objective of development" [1:43].

Development in OCF effectively means, everything we do that contributes to need satisfaction, while sustainability simply means continuance. It is with these meanings in mind that the OCF definition of sustainable development has to be read. No other interpretation is possible so that the 'Brundtland' definition below should never be quoted out of context, "Sustainable development is development that meets the needs of the present without compromising the ability of future generations to meet their own needs" [1:43].

From this form of words, it is apparent that the development path that is sustainable is the one that preserves the means for meeting needs in tact for future generations. This is not an opinion but a universal principle that in practice means:

(1) Choosing to do the things required to meet our needs in a way that preserves the resource base and,

(2) Choosing to preserve the rights of everyone to an equitable (fair and just) access to that resource base.

The SD of OCF then, is nothing more than the reiteration of an age-old principle of good husbandry that says, 'if you want to continue living then look after your resources'. Or according to Hicks, [8] live off the real income from your capital and not from liquidating the capital itself. By including the equity clause, the OCF definition goes even further.

\section{Is Sustainable Development a world ideology with its own myths? [9]}

The presentation of SD in OCF is rigorous and explicit and explains clearly and exactly what sustainable development is, so it is puzzling to see so many opinions and so much misinformation surrounding the concept, calling it vague, ambiguous and even labelling it an oxymoron [4]. The irrefutable principle of SD is a fact of life that has fallen under a pall of opinion, conjecture and multiple definitions. These distortions are related in no small way to the practice of cutting off the basic concepts of sustainability, development and environment from their moorings established in OCF and allowing them to meander unchecked into all sorts of representations such as the popular three- pillar model of SD itself.

\footnotetext{
${ }^{1}$ This is contrary to the curious practice of equating sustainable development with sustainability for no apparent reason and claiming that the OCF definition, that explicitly defines sustainable development, actually defines sustainability?
} 
Some say that the appearance of this three-pillar 'Venn' diagram model is more to do with intuition rather than hard logic. What ever the reason, this distorted representation, has been accepted hook line and sinker by the good and the great, by governments national and local, by the British Standards Institute [5] and Higher Education, [6] by the World Bank [10] and the United Nations [11]. Why? Perhaps groupthink is at work here ${ }^{2}$ Or maybe misplaced concreteness $?^{3}$ It is said that myths and ideologies emerge from a desire to see things as you would like them to be, idyllic, pleasing, satisfying and enduring, a lot to do with 'wishful thinking'. The same author [9] suggests that sustainable development is another world wide ideology supported by various myths. He list 10 such myths but nowhere does he address the greatest apparent myth of them all, namely that SD can be represented by three pillars or by a 'Venn diagram' (Fig. 3), where the SD comes to pass as environmental, social and economic advantage somehow come together in a win-win triple synergy through a balancing exercise [12]. Whether indeed this is pure myth or whether there is some logical truth in the TBL representation needs more stringent clarification, but as we shall see the dichotomy of development has an altogether more straightforward explanation.

\section{Fathoming the dichotomy - the final 'chapter'}

The key to fathoming the dichotomy of the two conflicting representations of sustainable development lies in the pages of OCF and in the refocusing of the fundamental concepts of environment and development. Development in particular needs special attention. In the widest sense of the word it is "what we all do in attempting to improve our lot" (our emphasis). The popular view of development owes a lot to history. In fact our whole system of production and consumption is built on an historical inheritance.

\section{Inheritance 1 the Take - Make - Use - Discard linear ex- ploitation path}

What did the Romans do to "improve" their lot? The Romans and those in the same ilk laid down a template for a development path dependent on the exploitation of resources. (Survival of the fittest and exploitation of others, something addressed by the practical application of the equity clause in the OCF definition) Such a course of action is justified it seems by the apparent abundance of resources as viewed from the ancient world. Characterised by a move from cyclic conservation to linear exploitation this model for 'improving your lot' and getting wealthy based on a Take-Make-Use and Discard, philosophy has endured till today. This 'way of doing things' characterised in its early stages by colonialism, the industrial revolution and even the slave trade has now become ingrained into the current socio economic system.

We have inherited an unsustainable linear developmental path that has become entrenched at the core of our production and consumption [1:xii] and we still do TakeMake-Use-Discard as a matter of course. For example, the textile industry with its 'fast fashion', with clothes discarded en-mass at one end and the devastation of exploitation and pollution at the other is reminiscent of the way the Romans sucked the nutrients out of north Africa which "through the stomachs of the Romans ended up in the Mediterranean" [13].

\section{Inheritance 2 Gross National Product}

During and following on from the Second World War Gross National Product was invented to count up the financial flows circulating in the economy to measure economic activity. Derived from the processes and activities of 'wealth creation', the unsustainable nature of such activities is not actually noted in the GNP figure.

Economic success is related to the size and not the nature of the 'wealth creation' activity. One economist refers to GNP as a veritable Frankenstein [14] egging us on to ever more production and consumption regardless of the constraints of nature, the linear processing and the GNP indicator mutually reinforcing each other.

Inheritance 3 One problem one solution; reactive 'pollution' control

Current environmental management is reactive in nature, problems being dealt with as they arise according to the feedback loop illustrated in Figure 1 below.

In 1952, a 'pea-soup' smog engulfed London for four days, smoke from coal combustion, fog and weather conditions conspired to limit visibility to a few feet, the smog even ingressing indoors. Several thousand deaths from respiratory and related medical conditions occurred. In 1956 the clean air act introduced measures such as smokeless zones, fuel switching and tall chimneys to deal with the condition. It took another 4 or 5 years to implement and to achieve significant improvements (Figure 1).

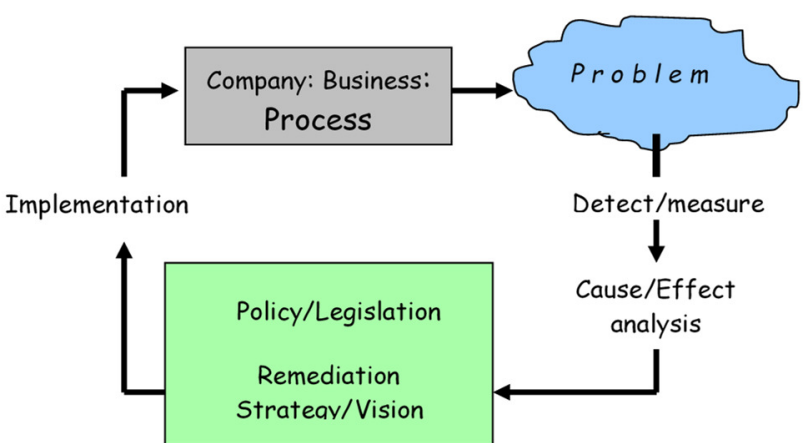

Fig. 1 Problem orientated environmental management feedback loop

In the meantime, in 1957 the treaty of Rome established the common market. The European Economic Community (EEC) was purely an economic organisation for trade and wealth creation with no official stance or plan regarding environmental protection.

\footnotetext{
2 Essentially Groupthink occurs when a group makes faulty or ineffective decisions just for the sake of reaching an agreement. The social psychologist Irving Janis 1972 used the term to describe suboptimal decisions made by a group due to group social pressure. (Wikipedia)

${ }^{3}$ The error of mistaking the abstract for the concrete; TBL mistaken for actual sustainable development.
} 


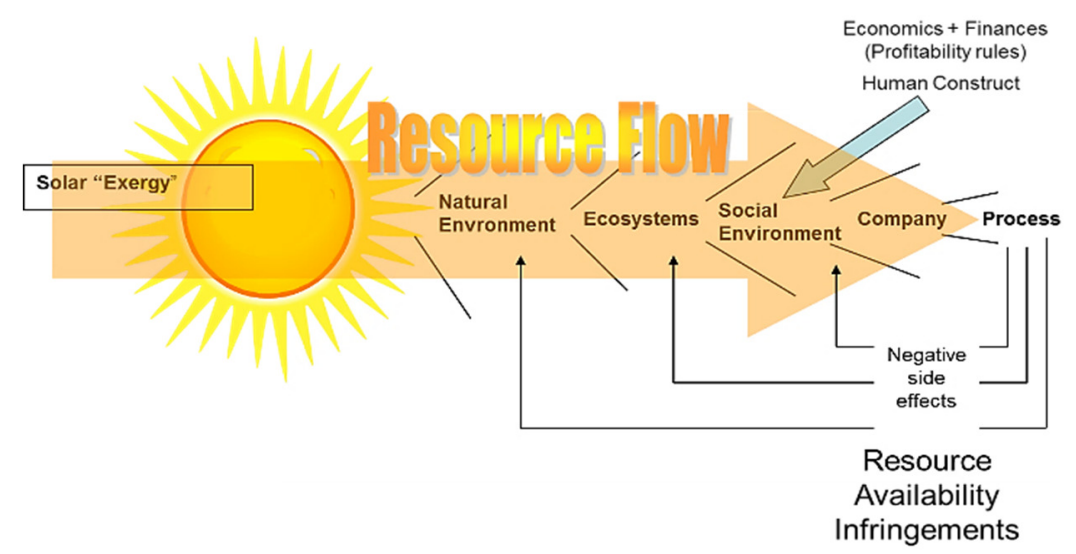

Fig. 2 The Surroundings of a business (a company) and its processes

Not until the 1970ies did The EEC adopt its first Environment Action Program. Acid rain episodes and the growing menace of climate change each provoked its own feedback response so that as environmental issues arose, responses followed, establishing a pattern of reactive problem orientated pollution control along the lines of one problem one solution each within its own feedback loop. The environmental reactions appearing as problems and pollution episodes seemed to catch all by surprise, but the problems needed to be sorted so that business as usual could continue. The pattern has repeated itself ever since setting the scene for the current one problem one solution management strategy.

\section{Inheritence 4 The Business Dilemma}

A company or organization finds itself in the path of two major defining and conflicting realities. On the one hand the business is embedded in a social and natural environment that defines and constrains its activities (See Figure 2) while on the other hand, the company is also driven by a framework of economic rules that define its profitability.

Both constraints are real, but unless the economic driver properly takes into account the same environmental constraints that bind company activity, the company will find itself in a dilemma as shown in Figure 3 below.

Constraints from the environment translated into legislative pressures are in opposition to the main thrust of the economic profitability driver that still largely rewards unsustainable behaviour such as an increase in throughput. The original linear production and consumption model is much in evidence here, driven on by GNP pressures that give little regard to resource availability or to sustainable processing.

Management in its fullness has to consider all the surroundings within which a process or a company operates. This includes the man made limitations of profitability and finance and the resulting business dilemma that will only be overcome when economic rules are remodeled along the lines of a sustainability ethos so that sustainable processing is made profitable (See Table 1).

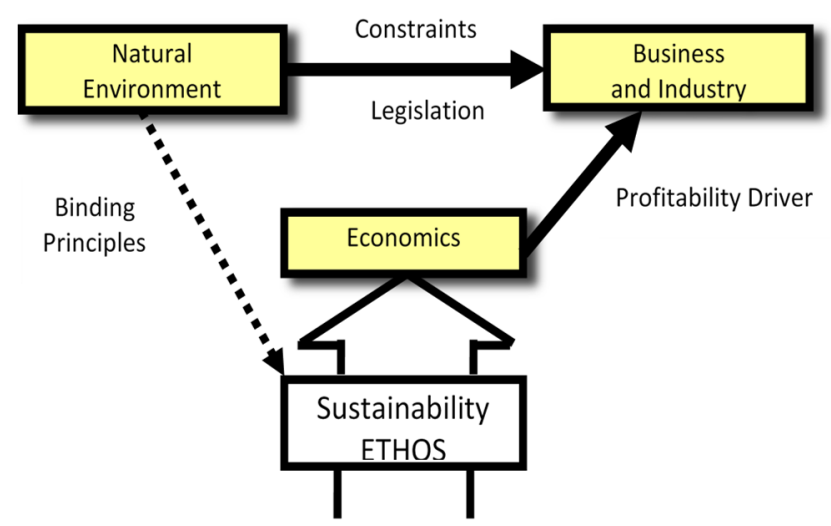

Fig. 3 The business Dilemma

As illustrated by mounting environmental problems, the linear production and consumption system aided and abetted by the GNP indicator has hit the buffers. This development path is so ingrained in our way of living that to reverse it and make it environmentally benign will take some doing. In view of this and in view of the reality of the business dilemma, the current management of the interactions between processing and its surroundings depends on tolerating a certain amount of environmental degradation in return for the desired socio-economic progress. A compromise, trade-off rout is apparently the only practical way forward. The following quote sums it all up.

"In the first decade of the new century, the issue of human impacts on global climate change has mostly been framed within a broader debate about sustainability. The challenge of doing something about this and other global issues (such as biodiversity depletion and pollution), while simultaneously tackling global inequality and poverty and not letting the wheels come off the world economy, is labelled as sustainable development" [12:2]. 
Sustainability and SD criteria within ISO14001 (2004) for TSM

\section{EMS (ISO 14001) (2004)}

\section{definitions}

3.5 environment.

Surroundings in which an organisation operates, including air, water, land, natural resources, flora, fauna, humans and their interrelations.

3.6 environmental aspect.

Element of an organisation's activities or products or services that can interact with the environment. (4.3.1 below)

Scope...the management applies to those environmental aspects that the organisation identifies as those which it can control and those which it can influence

\section{Procedures and Methods}

A3.1 Changes to the environment either adverse or beneficial that result wholly or partially from environmental aspects are called environmental impacts. The relationship between the two is one of cause and effect.

\subsection{Continual Improvement.}

Recurring process of enhancing the EMS in order to achieve improvements in environmental performance consistent with the organisation's environmental policy.

4.3.1 Environmental Aspects

The organisation shall establish, implement and maintain a procedure(s).

(a) to identify the environmental aspects of all its activities, products and services......

(b) to determine those aspects that can have significant impact(s) on the environment

\section{Environmental Policy}

3.11 Environmental Policy Overall intentions and direction of an organisation (3.16) related to its environmental performance (3.10) as formally expressed by top management.

The environmental policy provides a framework for action and for setting environmental objectives (3.9) and environmental targets (3.10)

\section{What is being managed?}

Adaptation of EMS for sustainability management

The interaction of 1. The "way we do things". The developmental activities and processing over an organisation with the environment.

The kernel of the management system is the environmental aspect

The scope of application is user defined.

Management hinges on the actual relationship between an environmental aspect and a resulting impact.

The degree of improvement is user defined and does not "guarantee optimal environmental outcomes"

User defined procedures to identify "important" aspects of their operations that they wish to manage. Those having a serious effect on the environment. (That they can control)

Policy is a central document confirming the commitment of the whole organisation to achieving environmental excellence. It ought to be a driver for action the entire cradle to grave extent of business operations.(Figure 7)

2. The interaction of the entire business operation with the "surroundings" especially the resource base that sustains it, the profitability rules that make it viable and the social and natural environments within which the business is imbedded. (Figure 6 surroundings)

Sustainability aspects of a business are elements within a business operation (over the entire cradle to grave extent) that lead to the undermining of the resource base on which they depend. (That have identifiable RAIs)

Sustainability risks can come from anywhere within the entire cradle to grave extent of operations. Risk originates either within the factory itself or is imported into the factory from the supply chain, from the use phase of the business goods and services or from support processes such as transport and energy generation lying outside the factory. The scope includes all of the above. (Figure 7)

A sustainability risk exists when a sustainability aspect is linked to a resource availability infringement. (RAI).

For example,

- An operational element within the factory undermines human health or air quality availability.

- Outside the factory, elements within power generation using fossil fuels undermine the availability of a stable climate.

- A poor-quality or environmentally inappropriate product will undermine market opportunity.

Adoption of a proper absolute goal is vital for management effectiveness The desired goal of (Total) sustainability management is a condition of Zero RAls where all sustainability risks have been eliminated. (Similar to zero defects in TQM). Back casting from this goal sets the improvement path to be followed. A path that is facilitated through the Plan-Do-Check-Act iterative loop of ISO14001, where the sustainability policy is central.

Risk exists whether it can be controlled or not.

A comprehensive awareness of the sources of sustainability risk throughout all business operations is vital for effective management, as is the identification of sustainability hot spots that pose a significant risk to business viability. Significance is determined through a risk assessment procedure to set priorities for action within the improvement strategy. Some high priority actions are relegated in importance because of economic considerations. (Business Dilemma Figure 2) In TSM, economics has to be removed from the initial assessment whenever profitability rules reward unsustainable activity. A second priority list is drawn up according to economic viability.

\section{Sustainability Policy}

Sustainability Policy.

Is the overall intentions and direction of an organisation with regard to its sustainability performance

A sustainability policy, the management driver, is centred on the most serious sustainability risks, with the associated objectives and targets.

Facilitated by successive management iterations, policy updates drive the 'development' path along a strategy of continuous improvement, mapping out actions that aim to diminish and eliminate the identified RAls, throughout the whole cradle to grave extent of an organisation's operation, moving towards total sustainability.

Source: [3] 
Such a purported 'sustainable development' is illustrated in the well-known 'Venn Diagram' Figure 4 below. The World Bank likewise advocates a balance, a tradeoff as a strategy for SD. [10].

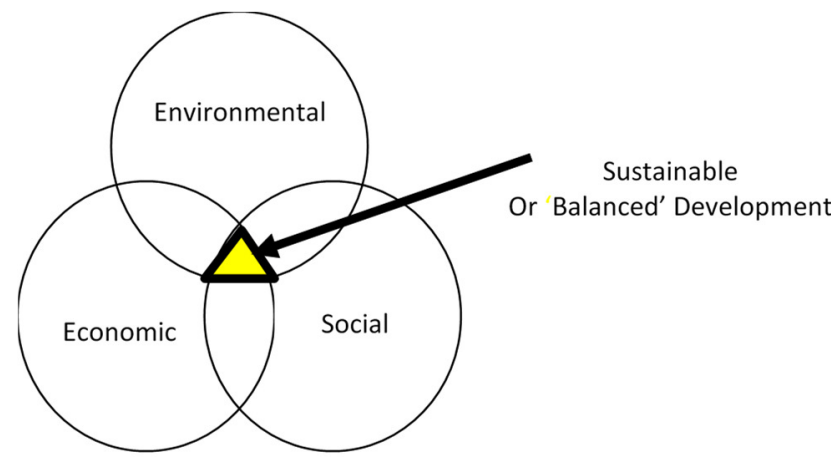

Fig. 4 The well-known 'triple bottom line' 'Venn' representation of $S D$

How deeply this particular response to the challenge of SD has become ingrained as an ideology is well illustrated by the practice in Poland of referring to SD as a 'balanced' development (rozwój zrównoważony), a reference to the balance of compromise and trade-off between economic wealth creation and environmental and social integrity. This approach can be the only way forward in the face of the predicament of un-sustainability that is upon us, requiring a "massive shift in societal objectives" [1:363] and a fundamental redesign of the entire production-consumption system.

The TBL development path, the three-pillar depiction of sustainable development shown also as the 'Venn' representation, is simply a trade-off balancing act carried out to make the best of a bad job, (Path (1) on Figure 5. It is NOT sustainable development.

In summary, therefore, the contemporary development path inherited through history and based on resource exploitation is unsustainable by definition [1:xii]. It leads directly to the 'business dilemma' so that the management of the interaction of developmental processes with the environment must necessarily result in a trade-off between them. For that reason, with the best will in the world, the three-pillar TBL representation cannot be sustainable development because this balancing act always leaves a semblance of unsustainable processing in-tact.

We are dealing with two distinctly different development paths, (1) the OCF path that is authentically sustainable and (2) the TBL path that is unsustainable by definition but that is masquerading as an authentic version of sustainable development. The adapted 'Pearce' diagram (Figure 5) [15:46] illustrates this very graphically. It is the TBL masquerade that is the real oxymoron [16].

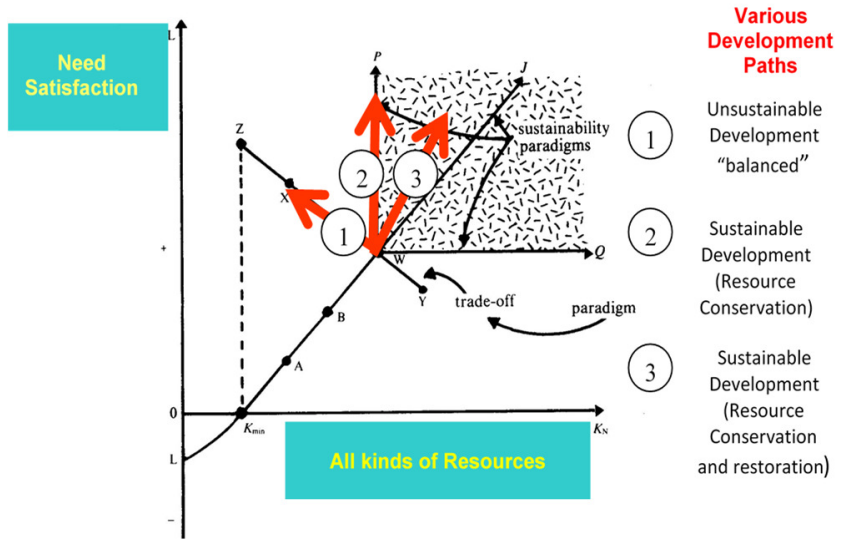

Fig. 5 Sustainable and unsustainable development paths

Source: Adapted From: Economics of Natural Resources and the Environment: 1990.

\section{ISO 14001 (2004) THE VEHICLE FOR SUSTAINABILITY MANAGEMENT}

Rising to the challenge of sustainability management View of reality

Environmental management has in current practice, become problem orientated where problems are 'sorted' as they arise, while the processes, causing the problems, are only affected by default. Some management measures don't even affect the source process at all. Tall chimneys recommended in the 1956 clean air act to throw the effluent higher up into the atmosphere where it could be more easily dispersed, do nothing to tackle the combustion process lying at the source of the problem. Such feedback management is slow and cumbersome and is easily outpaced by the rate of new environmental insults appearing.

The Sustainability management based on the TBL vision of SD likewise is problem orientated. The approach envisages a trade-off of environmental social and economic ills against each other. These problems however can all be traced back to the side effects and sustainability deficiencies of the underlying processing, and that is where management should actually be concentrated (Figure 6).

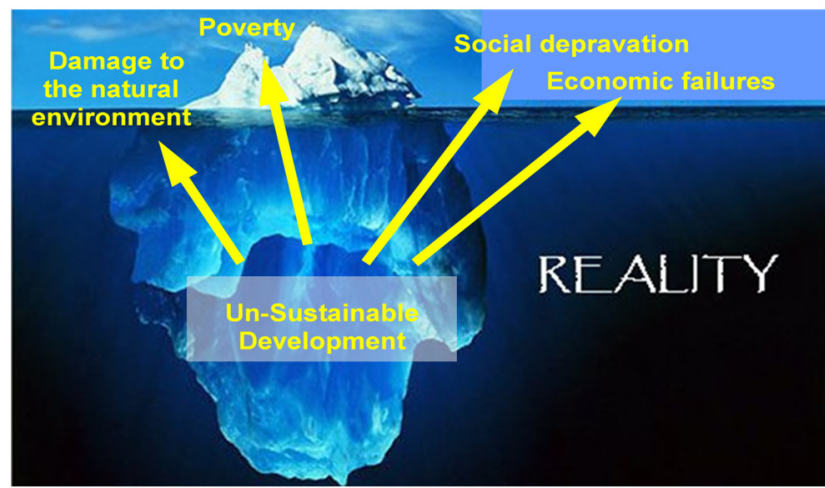

Fig. 6 Un-Sustainable Development the source of environmental and socio-economic problems 
The sustainability of the underlying processes and the other activities of development need to be restored through management that is process orientated that gets to the nub of the matter directly. Unlike the current reactive 'symptom' management, plan $A$, that waits for problems to occur first, plan $B$ is proactive and aims to set up process activities that are inherently sustainable by design.

\section{Total Sustainability Management}

From part 1 of this paper we know that the defining property of sustainability and its core meaning is continuance 'the ability to go on' indefinitely and that the continuance of a development path is crucially dependent on the way it treats resources

The required mechanism that describes the interaction of a process with the surroundings, the subject of sustainability management, can be illustrated as shown in Figure 6 . The mechanism is centred on the negative side effects of processing that can go on to undermine the availability of the inflowing resources needed by society. Sustainability is a property of the process or activity and a process is sustainable when it has no such associated Resource Availability Infringements. (RAIs) Finally it is apparent that sustainable processing is the basis of sustainable development and that it also lies at the heart of the long-term sustainability of a company. In all these cases the same sustainability criterion applies that depends on the existence of RAls.

Total Sustainability Management (TSM) modelled on Total Quality Management (TQM) [17] is the preferred approach for sustainability management because it includes, like TQM does, an absolute goal. (Zero RAI in TSM corresponds to zero defects in TSM) Sustainability management is a journey and has to have a concrete destination as well as a direction of travel.
Management extends to everything that surrounds a business, which is the social, natural, and economic context within which the processing activities function. Figure 6 shows the management context.

Processes reside within the company and both are embedded in society and ultimately in the natural environment. Resources that are the life-blood of the processing and of the company flow from higher nested elements driven by solar exergy [18]. The negative side effects that undermine the availability of these resources are the RAls that have to be eliminated through TSM.

OCF implied that the environment is more than just oceans, forests and mountains, a theme picked up in ISO14001 (2004) where the environment is actually defined as the "surroundings within which an "organization (3.16) operates, including air, water, land, natural resources, flora, fauna, humans and their interrelation," (see Table 1).

All the activities within company operations especially the production and consumption processes it is involved in lie at the interface between the company itself and those surroundings. This is the coalface of company operations where engineers have to operate right across its cradle to grave extent (Figure 7) including those inside and those outside the "factory fence".

In the engineering context, the purpose of TSM is to progressively remove all RAls across the entire cradle to grave extent of company operations (Figure 7) until the final goal of zero RAls is reached.

Figure 7 shows a generalised 'cradle to grave' process flow diagram of a production system to be managed in TSM. Internal aspects such as washing, storage, packing, production processes $A$ and so on, as well as external aspects like power generation, transport, raw materil acquisition and the poduct use phase are managed for sustainability within the ISO14001 (2004) iteration loop (see Table 1).

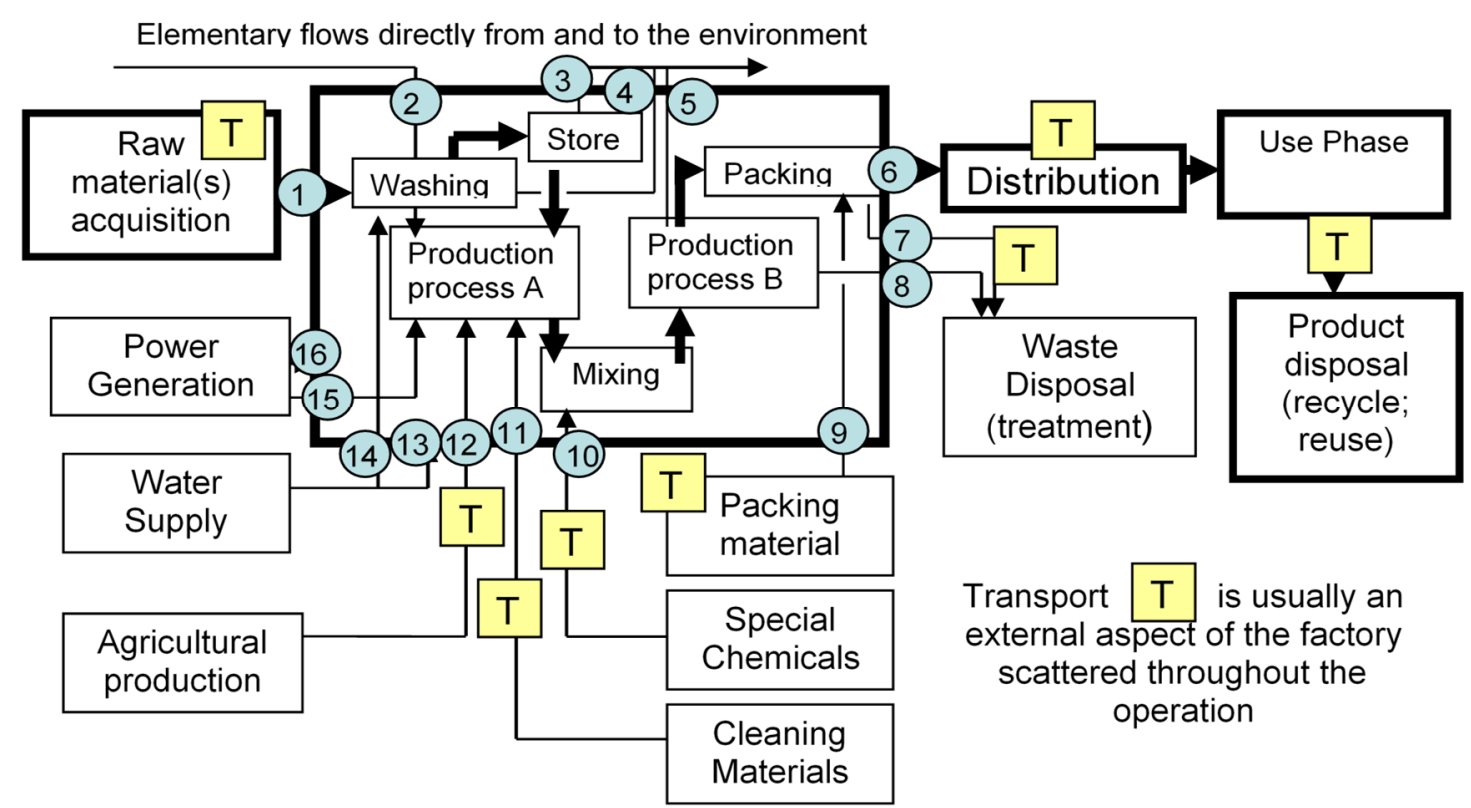

Fig. 7 'Cradle to grave' extent of a company operation to be managed 
All RAls for these processing activities are progressively elliminated from the system by process redesign, effluent 'end of pipe'measures and the like. The strategy to accomplish this is the subject of the sustainability policy. To deal with the business dilemma, in TSM, a priority action plan is drawn up purely on the basis of sustainability in a "sky's the limit" scenario without economic considerations. This identifies what needs to be done, what RAls need to be elliminated to close the real sustainability gap between current operation and a Totally Sustainable version of company operations. To assess the effect of the business dilemma, a second action plan is set up with rearranged priorities due to economic constraints.

Although ISO14001 (2004) has been withdrawn as a management standard, its simple framework is perfect for our purposes. The kernel of the system is the 'Aspect' or processing activity that is the source of environmental impact. Within the management system, strategies are drawn up to eliminate the effect of such impacts, guided by the policy document, a statement of intent that includes objectives and targets for each significant impact. The procedure is an iteration regulated and updated via a management review until the goal of the management is reached. The Table 1 below is a summary of the way sustainability criteria are fed into the ISO14001 (2004) framework.

\section{DISCUSSION}

According to OCF the sustainability or continuance of a development path is explicitly dependant on the way that it treats resources. The reality of the business dilemma means that the TBL representation of SD still contains resource exploitation at its core so it cannot be real SD at all, disqualifying it from use as a mechanism for sustainability management. A real sustainable development path on the other hand looks after its resources. This is central to the proper management of the sustainability of development and its associated processes and activities and forms the basis of an effective practical mechanism to be fed into a management framework. TSM deals with every processing activity throughout the whole 'cradle to grave' extent of company operations and requires that all RAls be removed. Sustainable processes moulded by TSM are the basis of a sustainable company and contribute directly to a sustainable economy.

\section{CONCLUSION}

Management of sustainability or SD by seeking some kind of win-win synergy between three categories of problems, ecological economic and social, is a nonstarter for three reasons. Firstly, the concept is an abstract open to a great many interpretations, secondly it is problem orientated and thirdly and most importantly, the 'Venn' representation is not SD at all.
This is no basis for a rigorous management solution. Plastic pollution, climate change, poverty, deforestation, sand shortages, the crisis of biodiversity, the demise of insect populations and so on, are all down to the Take-Make-Use-Discard un-sustainable basis of production and consumption. The processing is wrong and has to be fixed as a matter of priority.

Politically, barring a paradigm shift, it is not likely to happen any time soon, but TSM offers a rigorous process orientated management approach based on the real SD of OCF. Here resource conservation and availability is central, as it should be providing an indispensable tool striking at the heart of practical sustainability and SD. It's time to get real.

\section{REFERENCES}

[1] G. Brundtland. Our Common Future WCED. Oxford University Press, 1987.

[2] J. Porritt. Capitalism: As if the world matters. Earthscan, 2005.

[3] ISO.14001 (2004) "Environmental management systems Requirements with guidance for use." Internet: https://ocw.unihe.org/pluginfile.php/3158/mod_resource/content/1/ISO_14001.pdf ,2004[Feb, 2019].

[4] S. Boroń. "Will the real Sustainable Development please stand up an introduction" Internet: https://www.polsl.pl/Wydzialy/ROZ/ZN/Docments/z\%20122/Boro\%C5\%84.pdf, 2018[Feb 2019].

[5] A. Henriques. Sustainability, A manager's guide. UK. British Standards Institution, 2001, pp. 31-51.

[6] Higher Education Academy and QAA. "Education for Sustainable Development - guidance for UK higher Education Providers" Internet: https://www.qaa.ac.uk/ docs/qaa/quality-code/education-sustainable-development-guidance-june-14.pdf?sfvrsn=1c46f981_8, 2014[Feb 2019].

[7] H. E. Daly. Ecological Economics and Sustainable Development, Selected Essays of Herman Daly. Edward Elgar Publishing Limited, 2007.

[8] Salah El Serafy. Microeconomics and the Environment: Essays on Green Accounting. Edward Elgar Pub.USA, 2013.

[9] W. Sztumski. "The Mythology of Sustainable Development". Problems of Sustainable Development. Vol 4 No 2, pp13-23, 2009.

[10] Tatyana P. Soubbatina. Beyond Economic Growth; An Introduction to Sustainable Development. WBI Learning Resource Series The World Bank, 2004, pp. 7-11

[11] United Nations. "Resolution adopted by the General Assembly (2005) A/RES/60/1" Internet: www.refworld.org/docid/44168a910.html, 2005[Sep 2018].

[12] W.M. Adams. "The dilemma of sustainability" in Green Development, Environment and sustainability in a developing world. $3^{\text {rd }}$ Ed.Routledge London and N York, 2009.

[13] J. Seymour; H. Girardet. Far From Paradise -The Story of Man's Impact on the Environment. BBC, 1986.

[14] L. Fioramonti. Gross Domestic Problem: The Politics Behind the World's Most Powerful Number, Zed Books, 2013. 
[15] David W. Pearce and R. Kerry Turner. Economics of Natural Resources and the Environment. Harvester Wheatsheaf, 1990, pp. 43-48.

[16] J. H. Brown. "The Oxymoron of Sustainable Development". BioScience, Volume 65, Issue 10, pp.10271029, Oct 2015.

\section{Dr Stefan Boroń}

Heriot-Watt University, Chemical Engineering, School of EPS, Edinburgh. EH14 4AS, Great Britain e-mail: s.boron@hw.ac.uk

\section{Dr Tomasz Kosiek}

Silesian University of Technology Faculty of Organization and Management Department of Applied Social Science ul. Roosevelta 26, Zabrze, Poland e-mail: tomasz.kosiek@polsl.pl
[17] Philip B Crosby. Lets Talk Quality. McGraw-Hill, 1989.

[18] James J. Kay. "Ecosystems as Self-Organising Holarchic Open Systems: Narratives and the Second Law of Thermodynamics" Handbook of Ecosystem Theories and Management, CRC Press - Lewis Publishers, 2000, pp 135160. 